\title{
Reflections on Sigurd P. Ramfjord: His Contributions to Evidence-Based Periodontics*
}

\author{
Major M. Ash ${ }^{\dagger}$
}

As a student, friend and colleague of Sigurd P. Ramfjord for almost 50 years it is a pleasure to reflect on some of his many contributions to periodontics. In many respects he practiced evidence-based principles long before the term "evidence-based" became a part of the recent emphasis on this approach to periodontics. What's more, he applied the concept not only to clinical practice but to the conduct of research as well. How "Sig" came from another life and another country to become a major scientific figure ${ }^{1}$ in periodontics is an interesting series of events and associations that blended his curiosity about the nature of things with ongoing medical research at the University of Michigan.

\section{Sig's Roots}

As with many honored people, Sigurd Peder Ramfjord came from what might be considered to be an unlikely place-a farm in a small community in Norway called Kolvereid. Although his family was involved in farming and in building fishing boats, Sig had his sights set on becoming a dentist. After attending the Dental College of Oslo University he practiced for 12 years but recognized that clinical practice did not satisfy his curiosity about the nature of periodontal disease, as well as the scientific basis for its diagnosis, prevention, and treatment. It was then that Sig left Norway to come to the School of Dentistry, University of Michigan.

\section{Factors Influencing Dr. Ramfjord}

When Dr. Ramfjord came to Ann Arbor several factors set the stage for the direction of his studies and research. Perhaps the most compelling was his association with Dr. Don Kerr as a graduate student in the Department of Oral Pathology which included at that time a large biopsy service, periodontics, and occlusion. Up to mid-century, approaches to the study of periodontal diseases were mainly descriptive, both clinical and histopathological. The latter method was to study autopsy material and make studied assumptions about the cause of the effects seen in tissue sections. At the first part of the twentieth century,

\footnotetext{
* Based on a presentation at the Third Sigurd Ramfjord Symposium,

University of Michigan, Ann Arbor, October 16, 1999.

$\dagger$ School of Dentistry, University of Michigan, Ann Arbor, MI.
}

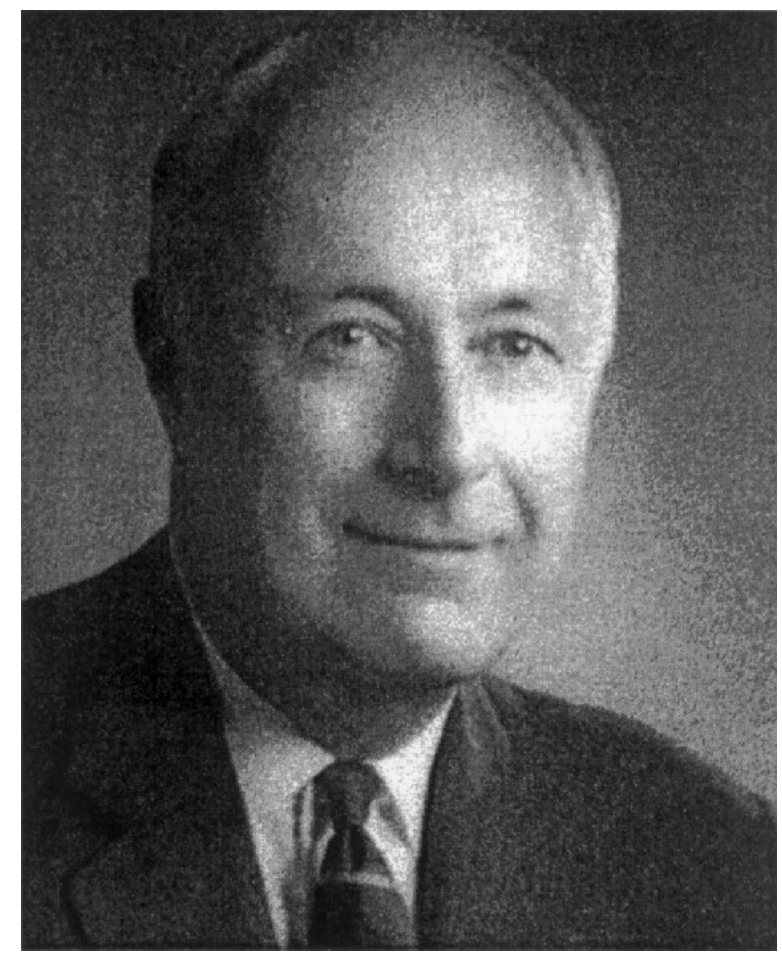

Sigurd P. Ramfjord, LDS, PhD, Dr Odont hc.

occlusion was considered to be important to an understanding of periodontal disease, e.g., studies on the effects of trauma on the periodontium, ${ }^{2}$ and on the initiation and/or progression of periodontitis. ${ }^{3}$ An example of the importance of histopathology can be seen in the material presented in periodontal texts before and at mid-century; e.g., Gottlieb and Orban, ${ }^{4}$ Glickman, ${ }^{5}$ and Orban. ${ }^{6}$

Professors Gottlieb and Orban, who were established researchers in Europe, came to this country to join the faculty at Loyola University, Chicago. They were well known for their concepts of periodontal disease. At periodontal meetings Sig was often at the front of those questioning their concept of periodontosis. For Sig, discussions about periodontics was a way of learning what others knew about his favorite topics. Perhaps the most interesting encounters were 


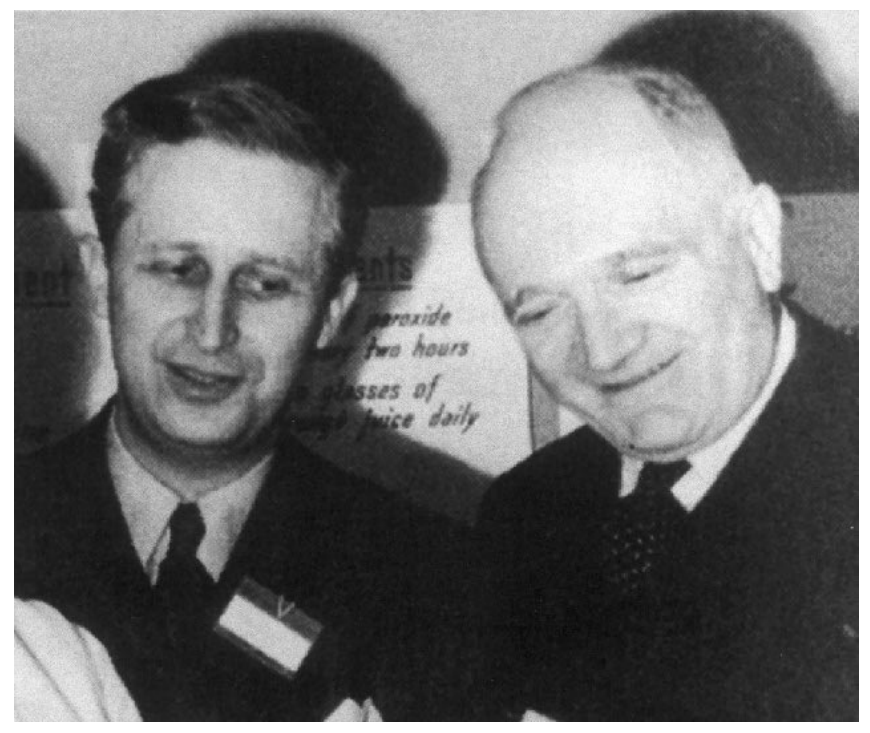

Drs. Balint Orban and Bernhard Gottlieb.

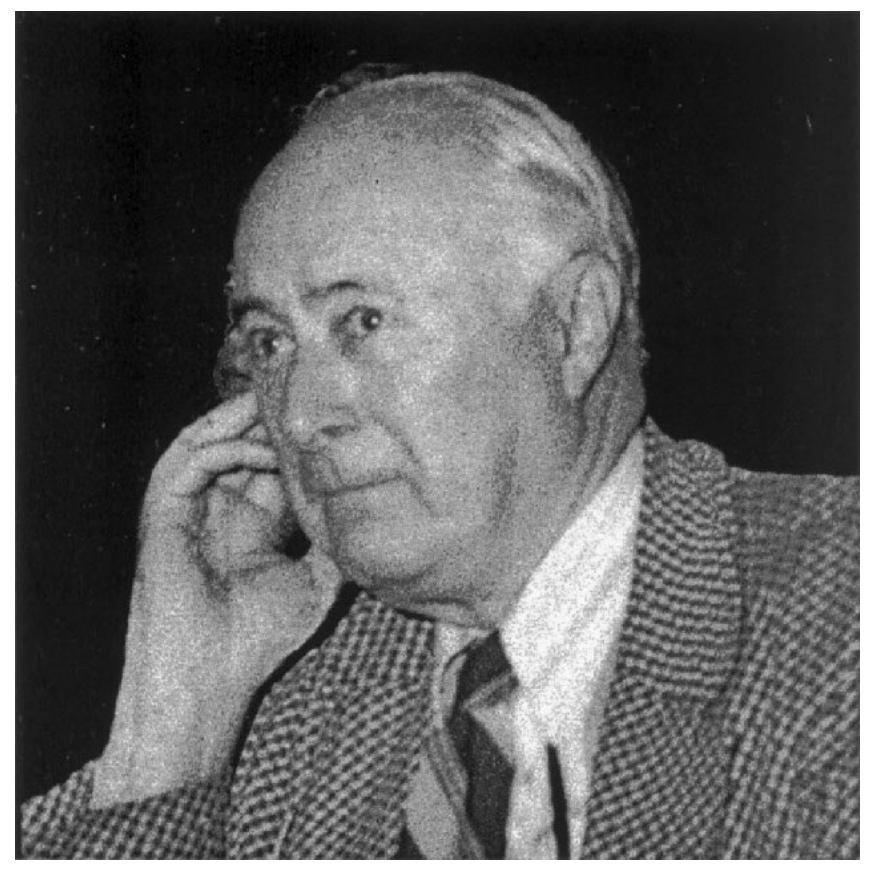

At meetings, Sig heard everything!

with Irving Glickman, who was also a serious debater. Sig was a careful listener at all lectures. He was always up front in view of the speaker and he didn't miss anything. Being fluent in Norwegian, English, German, and French was most helpful.
For Sig the authoritarian world of periodontology and research methodology was changing; e.g., descriptions of disease and theories based on sections of necropsy material were no longer scientifically adequate. That does not mean that histopathological studies were no longer useful; it did mean that causeand-effect relationships had to be addressed according to developing research methodology.

\section{Introduction to Research at Michigan}

When Sig came to Michigan it was a time when tuberculosis, diabetes, and poliomyelitis were being studied using animal models in the Department of Pathology at the University Medical Center. Also the epidemiology and prevention of these diseases were being addressed at the School of Public Health. For example, these diseases were transmitted to animals and their effects on tissues were evaluated by clinical, laboratory, and histopathological techniques. Into this arena Sig was introduced by Dr. Donald Kerr through his relationship with the Department of Pathology at the Medical School. Sig received his $\mathrm{PhD}$ in 1951 based in part on his dissertation, The Effect of Systemic Disease of the Periodontium of Rhesus Monkeys with Reference to Poliomyelitis, Tuberculosis, and Alloxan Produced Diabetes. Experimental Reattachment in Rhesus Monkeys. Several studies were published from this dissertation; e.g., "Effects of febrile diseases on the periodontium of Rhesus monkeys," 7 "Tuberculosis and periodontal disease," 8 "Reattachment in periodontal therapy, ${ }^{9}$ and "Experimental periodontal reattachment in Rhesus monkeys." 10 This scientific methodology remained with Sig throughout his animal studies on periodontal diseases, occlusion, and the temporomandibular joints.

\section{Influence of Dean Bunting}

Russell W. Bunting, Dean of the University of Michigan School of Dentistry, greatly influenced Sig's approach to the treatment of periodontal disease. For Dean Bunting, subgingival surgery ${ }^{11}$ or root curettage was a procedure that was effective for most people and the least offensive to the supporting structures. This concept of conservation of supporting structures remained with Sig throughout his professional career.

\section{Epidemiology: School of Public Health}

Another significant factor in Sig's professional direction was the ongoing work of Dr. Al Russell who was doing field studies on the epidemiology of periodontal disease. ${ }^{12} \mathrm{Al}$ Russell's association with the School 
of Public Health was a significant contribution to Sig's approach for studying the epidemiology of periodontal disease and the development of the periodontal disease index (PDI). ${ }^{13}$

\section{Jens Waerhaug}

One of the other significant influences on Sig's professional career was Jens Waerhaug's type of research on the gingival pocket. Although Jens and Sig developed a life-long friendship starting in dental school, they did not always agree on clinical periodontics. Ultimately Sig's research went beyond these studies but at the time they represented to him an approach to theories about the "epithelial attachment" that was the basis for an interpretation of the apparent incongruity between the histological and clinical concept of the gingival pocket. For Sig the nature of the epithelial attachment was important to an understanding of what was actually happening in healthy gingival pockets (crevices) and their pathological deepening. Jens' general conclusions were that "The possibility of reducing the depth of pathological pockets by means of curettage exists theoretically, but until further proof has been given, its practical value must be questioned." 14

Waerhaug's studies, along with Dean Bunting's conservative view of surgery, stimulated Sig's research into curettage, reattachment, reverse bevel Widman flap, and the significance of the position of the epithelial attachment in periodontal diseases. Waerhaug's clinical observations, ${ }^{15}$ which indicated that operator efficacy of subgingival curettage was significantly reduced if the depth of the periodontal crevice was greater than $3 \mathrm{~mm}$, were contradicted by the results of longitudinal studies at the University of Michigan. Sig's studies indicated that a gain of attachment level of 1 to $2 \mathrm{~mm}$ is possible with effective subgingival root curettage. ${ }^{16-18}$ Waerhaug's findings led to what Sig called the first of several dogmas that were used in daily practice by most dentists, even into the 1980s, though they were found to be partially or completely wrong. ${ }^{19}$ In short, the minimum crevice depth dogma implied that any periodontal crevice deeper than $3 \mathrm{~mm}$ (treated or untreated) could lead to progressive loss of periodontal disease in spite of good oral hygiene. This disagreement reflected the future dividing line between Sig's developing concepts of conservative therapy and other concepts that could lead to significant loss of supporting structures (e.g., ostectomy, ${ }^{20}$ osteoplasty $^{21}$ ) in order to obtain a $0 \mathrm{~mm}$ or even a $3 \mathrm{~mm}$ crevice depth.

\section{Treatment at Mid-Century}

If we look back about 50 years when Dr. Ramfjord first began his career at the University of Michigan, some who practiced periodontics did so with a lot of questions about all aspects of periodontal disease, including etiology, natural history, epidemiology, plaque, calculus, effects of instrumentation, curettage, crevicular fluid, etc. These questions were not limited to practitioners but were viewed as needing answers at the universities. Into this area at a research university, Sig found what he had been looking for and had not found in practice in Norway; i.e., a place to do research at both the clinical and laboratory levels to resolve some of the questions being asked by practitioners.

Instrumentation (debridement and root planing) and maintenance of oral hygiene were, and still are, the primary approaches to the treatment of periodontal diseases. The goal at that time for some periodontists was to remove all irritants, to have a root surface so smooth that irritating accretions were less likely to become attached to the tooth surface, and to allow the tissues to become tightly adapted to the tooth surface. If you had examined the root surfaces of the teeth instrumented by Robert L. Dement of Atlanta, or Russell W. Bunting of Ann Arbor, you would have found unbelievably smooth, glazed-like surfaces, free of any calculus and roughness. At this time the design of instruments reached a high level of perfection to reach all areas of the teeth; e.g., Gracey periodontal instruments. Maintenance of a close approximation of the soft tissue to the tooth was a goal and surgery, other than subgingival curettage, was not often a part of the mind-set for midcentury practitioners. But not all periodontal diseases are the same and the failures that occurred led research into all areas of periodontology and periodontics.

As was to be demonstrated in longitudinal studies at Michigan ${ }^{22}$ and elsewhere, ${ }^{23}$ the results of scaling and root planing are not significantly altered by soft tissue curettage performed either in conjunction with scaling and root planing ${ }^{24}$ or separately. ${ }^{25}$

As already indicated, Sig's PhD studies included studies on experimental reattachment in the Rhesus monkey. Subgingival curettage and reattachment were of considerable clinical interest at the time. Sig continued to undertake animal research at the Ann Arbor VA Hospital until his retirement. Sig was in the Department of Oral Pathology headed by Dr. Kerr, which explains in part his initial interest in histopathology of periodontal disease. 


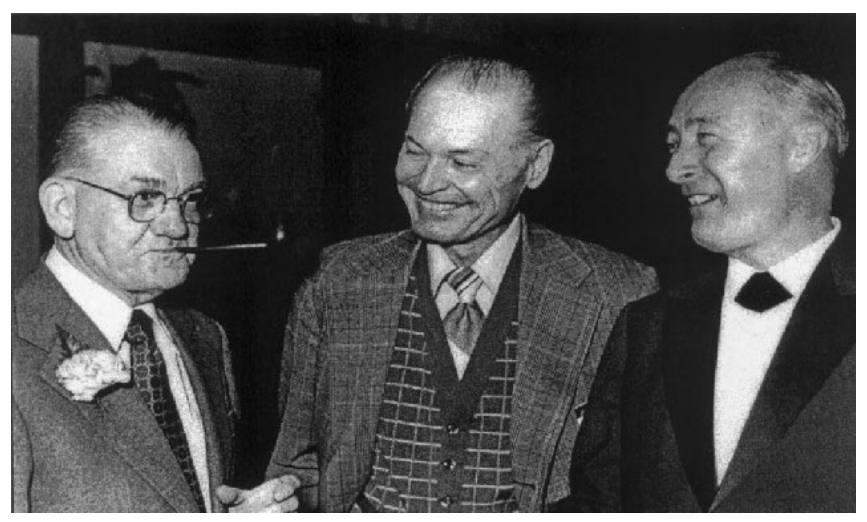

From left to right: Drs. Donald A. Kerr, Major M. Ash, and Sigurd P. Ramfjord.

The Department of Oral Pathology was the home not only of oral pathology and a biopsy service, but the source of future Departments of Periodontology and Occlusion. Dr. Ramfjord never lost his interest in studying the histopathology of periodontal diseases, both in humans and animals.

\section{Other Significant Influences}

Besides the background of histopathology into which Sig was introduced, another force played a major role in his professional approach to periodontics: a Workshop on Periodontal Disease under the direction of Dr. Kerr held at the University in 1951. The findings of the Workshop, under the editorship of Dr. Ken Easlick, were published in the Journal of the American Dental Association ${ }^{26}$ in 1952 . Two aspects of that Workshop were important for Sig; reports of evaluation committees for the Workshop that stated:

Based on objective observations can a valid index be established that will evaluate the gingival or periodontal status of individuals and of populations?

The lack of valid indices for determining the prevalence and epidemiological characteristics of periodontal diseases has hindered seriously the development of more effective preventive and treatment procedures for the diseases. ${ }^{26}$

These two statements were the basis for the development of a number of indices, including the periodontal disease index (PI) by A. L. Russell for epidemiological studies in very remote sites, ${ }^{12}$ and the periodontal disease index (PDI) by Sig Ramfjord for both epidemiological and clinical research. ${ }^{13}$ The lat- ter index was more precise in regards to probing depth and attachment level. It was used by Dr. Ramfjord in his early epidemiological studies in India, 27,28 and by Dr. Ash in Nubia. ${ }^{29}$ Although the PDI is a composite index, the periodontal probing of attachment level related to the cemento-enamel junction (CEJ) set the standard for scoring systems for evaluating periodontitis.

The validity of the PDI index, including the "Ramfjord teeth," was determined in several thesis studies. $^{30-34}$ Studies on the PDI conducted elsewhere have also demonstrated the validity of the Ramfjord teeth. 35,36

\section{Attachment Level}

The most important aspect of the index for all future evaluations of the periodontium relative to treatment was the introduction of the significance of the level of attachment for periodontal health. The use of a standard point of reference (CEJ) and a fine periodontal probe marked in millimeters provided a measurement that was isomorphic to the structure of arithmetic and appropriate for use in parametric statistical analyses. Treatments could be tested, longitudinal studies could be undertaken, and results could be compared (as demonstrated in the Michigan longitudinal clinical studies). The article on Sig's indices was cited in the literature nearly 400 times. ${ }^{13}$ At the time he was a rising star among research scientists in periodontology. Other researchers' indices of gingivitis and periodontitis began to be seen in the literature:

Massler/Schour P-M-A index (1952) 37,38

Russell: Periodontal Index (1956) ${ }^{12}$

Muhlemann \& Mazor: Sulcus Bleeding index $(1958)^{39}$

Ramfjord: Periodontal Disease Index (1959) ${ }^{13}$

Greene $\mathcal{E}$ Vermillion: Oral Hygiene Index $(1961)^{40}$ Löe: Gingival Index (1967) $)^{41}$

Only the Ramfjord index relates the level of attachment to the CEJ as well as the free gingival margin. Using the CEJ as the clinical landmark for assessing periodontal and gingival pockets was a unique feature that set the groundwork for evidence-based clinical trials. It is possible to say, perhaps arguably, that the modern era of periodontal epidemiology began with the use of these indices.

Historically, the modern era of periodontal research began in the mid-to-late 1960s when there was documentation of the bacterial nature of gingivitis and periodontitis. When viewing Sig's other contributions, 
it is easy to overlook his early involvement in bacteriological studies with Professor Mary Crowley. He was not a one-dimensional thinker, but laboratory techniques at the time were not up to the requirements for identifying unique microbes in the periodontal pockets.

\section{World Workshop in Periodontics (1966)}

At the Workshop in 1966, ${ }^{42} \mathrm{Sig}$ stated in his opening address that:

. . . during the Workshop [in 1951] it became painfully evident [to me] that the time was ripe to apply scientific methods to research in Periodontology and that the authoritarian era was over. $^{42}$

Then Dr. Ramfjord advanced the paradigm of research methodology which was the forerunner of evidenced-based periodontal practice:

Observation $>$ Experience

Concepts > Hypothesis

Experiments $>$ Establish Validity

This paradigm set the tone of the World Workshop in 1966. Sig clearly recognized that there was an ongoing paradigmatic shift about the way knowledge was obtained at the time of the 1951 Workshop and the way that knowledge was to be obtained in the future; i.e., the scientific method was becoming the basis for the conduct of all research in periodontology. It is not difficult to argue that Sig's paradigm was a glimpse of the future: an evidence-based practice of periodontics.

\section{Longitudinal Studies}

A series of clinical trials to evaluate the necessity or efficacy of periodontal procedures was begun in 1961 under the direction of Dr. Ramfjord at the University of Michigan. In addition studies by his graduate students were undertaken later at their own universities. In most of these studies the importance of periodic professional cleaning was evident in their design. These longitudinal studies at Michigan ushered in the quest to assess the value of periodontal procedures, especially those that involved resective surgery that might lead to unsightly root exposure, hypersensitive dentin, root caries, and unnecessary loss of supporting structures. As might be anticipated, Sig's quest to establish the scientific basis for periodontal procedure led to later quests by other investigators to challenge his concepts.

Although resective surgical removal of periodontal pockets had been used for some time, it gained

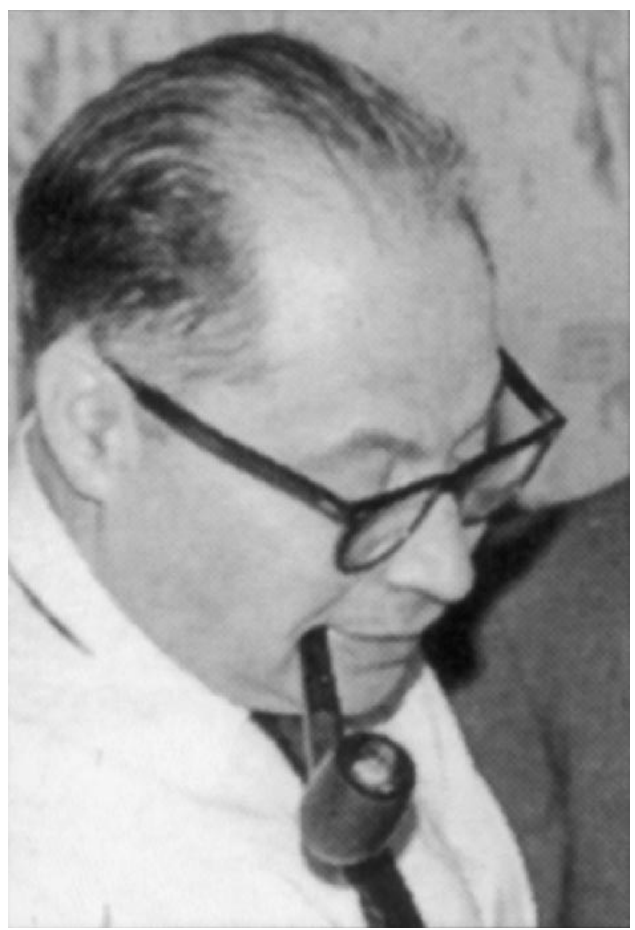

Dr. Irving Glickman.

momentum from Waerhaug's studies ${ }^{14,15}$ that the chances of removing subgingival plaque by closed curettage are small in pockets greater than $5 \mathrm{~mm}$ and are less than $50 \%$ in pockets 3 to $5 \mathrm{~mm}$ in depth. In addition, it was becoming evident on the basis of longitudinal studies ${ }^{43}$ that chances for connective tissue reattachment were inconsistent, but that, even in deep pockets, scaling and root planing alone provide as favorable a response as some surgical methods.

For the foregoing reasons, and others as well, partial or complete pocket elimination with resective surgery became a widely advocated therapy. The old saying "long in the tooth" was said to have been rephrased by Dr. Irving Glickman to: "Do you want your teeth longer or no longer?"

Gingivectomy or various flap procedures were utilized to eliminate pockets either totally with ostectomy or partially with apically repositioned flaps. The point zero dogma was for several decades the basis for debates on the appropriateness of resective periodontal therapy, especially those involving removal of bone.

\section{Sig's Goals for Therapy}

The maintenance of periodontal support was the principal goal of periodontal therapy for Sig, not zero 


\section{Guest Editorial}

depth at the expense of supporting structures. Sig's longitudinal studies showed that a post-treatment healed periodontal pocket may exist as a residual anatomical defect manifested as a crevice that can be penetrated by a thin probe for more than $3 \mathrm{~mm}$ without pain or bleeding and be stable over a long duration; e.g., in a longitudinal study of 8 years. ${ }^{44}$ Thus, periodontal pockets did not need to be reduced surgically to a $3 \mathrm{~mm}$ or zero limit to save teeth.

For Sig the critical consideration was not crevice depth. The concept of a "long epithelial attachment" (locus minoris resistentiae ${ }^{45}$ ) or epithelial adaptation evolved as a viable solution to periodontal treatment when combined with proper maintenance care. ${ }^{46}$ The key to successful maintenance of healed pockets with probeable depth beyond $3 \mathrm{~mm}$ is to be found in the altered bacterial flora in successfully treated pockets. ${ }^{47}$ On the basis of the Michigan studies, ${ }^{44,48}$ and those done at Gothenburg, Sweden, ${ }^{49}$ surgical elimination of pockets (including osseous surgery) offers no advantage for maintaining the teeth and their support over more conservative forms of treatment. From the Michigan longitudinal clinical trials, Sig was able to conclude that loss of clinical periodontal attachment in most instances can be prevented with professional tooth cleaning and topical fluoride applications every 3 months without regard to the effectiveness of the patient's home care. ${ }^{50}$

Dr. Ramfjord's longitudinal studies ushered in the modern concept of randomized controlled clinical trials for the comparison of various forms of periodontal therapy using objective forms of measurement and analysis.

\section{World Workshop in Clinical Periodontics (1989)}

Considerations of longitudinal periodontal probing were addressed at the 1989 World Workshop on Clinical Periodontics. ${ }^{51}$ One of the conclusions at that workshop was:

Statistically significant increase in probing attachment level is the gold standard for measurement of periodontal disease activity at a given site. ${ }^{52}$

Periodontal probing for attachment levels remains an important landmark for diagnostic strategy even though it does not immediately determine whether the disease is active, arrested, or in remission.

\section{Who Was Who in Periodontics}

In 1984 a symposium, "Periodontics Today-Perspectives of the Masters," was held at the University of Michigan. Speakers were Drs. Henry M. Goldman,

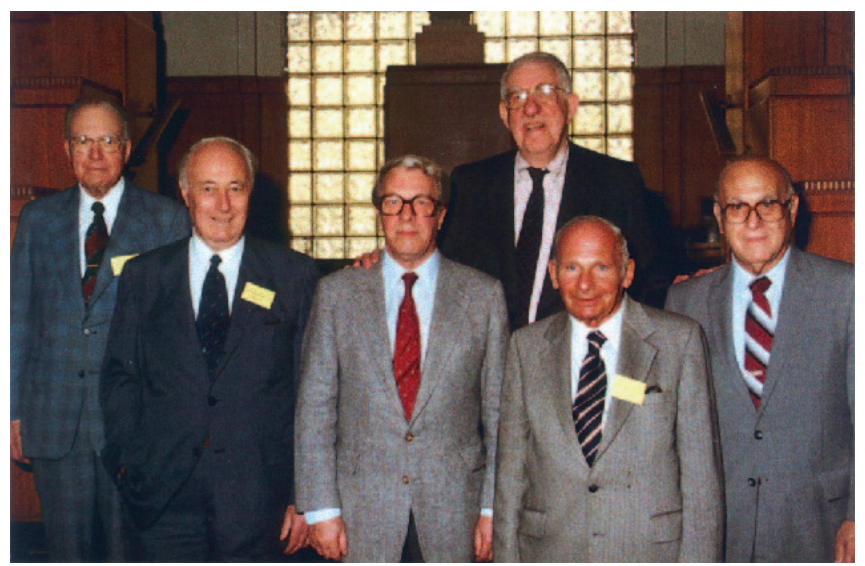

From left to right: Drs. John Pritchard, Sigurd Ramfjord, Harald Löe, Saul Schluger, Helmut Zander, and Henry Goldman.

Harald Löe, John F. Pritchard, Sigurd P. Ramfjord, Saul Schluger, and Helmut A. Zander. They represented the leading people in the field of periodontics and periodontology. The perspectives given at that time reflected the past, present, and future methods of research and management of periodontal diseases. It can be said that they were the forerunners of evidence-based periodontics.

\section{Occlusion and Periodontics}

One of Sig's interests was the relationship between occlusion and periodontics, especially occlusal periodontal trauma. When asked about the importance of occlusion, Sig stated that it should always be considered, but especially in the presence of moderate to advanced periodontitis, or progressive periodontitis, and any time where there is occlusal periodontal trauma. ${ }^{53}$ His interest in the significance of occlusal adjustment in periodontal disease is reflected in the many longitudinal studies done by the Michigan group, including a study reported by Burgett et al. ${ }^{54}$ which concluded that there "was significantly greater gain of clinical periodontal attachment in patients who received OA (occlusal adjustment) compared to those who did not."

\section{Changing Concepts}

For Dr. Ramfjord, periodontal paradigms were always going to change because knowledge was time dependent; i.e., dependent upon the scientific information available at a particular time. What was an anathema to him were the dogmas which persisted after they were shown to be partially or completely erroneous; ${ }^{19}$ e.g., crevices that can be probed clinically 
beyond $3 \mathrm{~mm}$ are progressive lesions previously untreated or treated. As already indicated, this dogma had a profound impact on periodontal treatment for many years. Closely related was the dogma that surgical sculpturing of gingiva and bone resembling horizontal atrophy to the level of the deepest defect is needed to stop further loss of support. Another dogma: complete plaque control by patients is necessary to stop the progress of periodontitis. To Sig's satisfaction, these dogmas had been proved incorrect on the basis of scientific evidence, from his as well as other studies. For Sig, these concepts were considered to be dogmas that needed to be overturned. Even so, it is still possible to see these concepts being advocated by periodontists. One can imagine the uncertainty of applicants taking the American Board of Periodontology with a mix of these concepts reflected by the Board members and in the examination questions.

\section{American Board of Periodontology}

Sig was a member of the American Board of Periodontology. Given the differences in opinion about the treatment of periodontal disease at the time, heated discussions took place; all in the interests of science, of course.

\section{Some Final Reflections}

Perhaps the most dominant aspect underlying Sig's accomplishments was his inherent ability to know what evidence was needed to resolve the theoretical and practical problems of periodontics. The use of the cemento-enamel junction as the reference for loss or gain of attachment turned out to be the gold standard of clinical research. The key to successful ther-

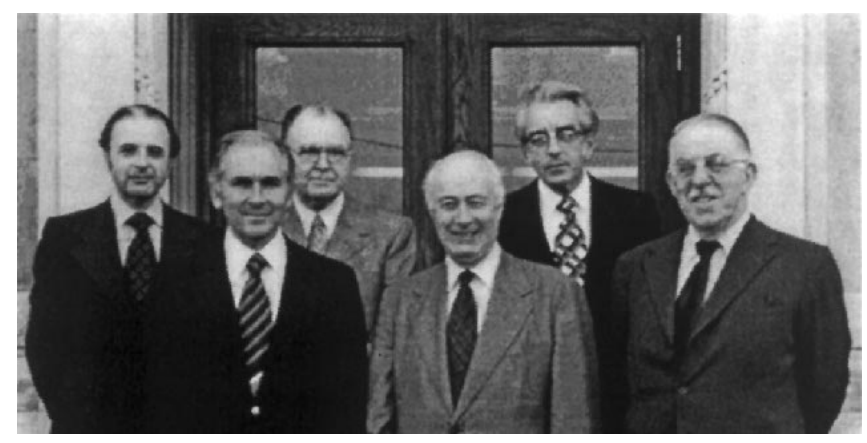

From left to right: American Board of Periodontology Directors Drs. Sigmund Stahl (1971-77), Gerald Kramer (1972-78), John Pritchard (1970-76), Sigurd Ramfjord (1969-74), Timothy J. O'Leary (197076), and Saul Schluger (1972-78). apy for him was effective root curettage and maintenance of the supporting structures of the teeth. Without this approach to longitudinal studies, measurement of the level of attachment and maintenance of the periodontium, there would not have been a "Michigan" concept of managing periodontal diseases. This dual-axis concept is even yet a solid target in a rapidly changing field. "Longitudinal monitoring of probing attachment level is a reliable method for determining the stability of the periodontal supporting structures." 55

There will always be a need to know what the level of attachment is even if it is possible to determine immediately whether a disease is active or not. Sigurd Ramfjord, through his PDI and ground breaking longitudinal clinical studies many years ago, set the cornerstone for evidence-based periodontics. Yes, for me, Sig was a "major scientific figure" in his time, and the "giant" among the "Masters" in periodontics and periodontology. The "Michigan" approach to the study and treatment of periodontal diseases will long be identified with Sig's concepts of accurate measurements, randomized longitudinal clinical trials, and preservation of supporting structures of the teeth.

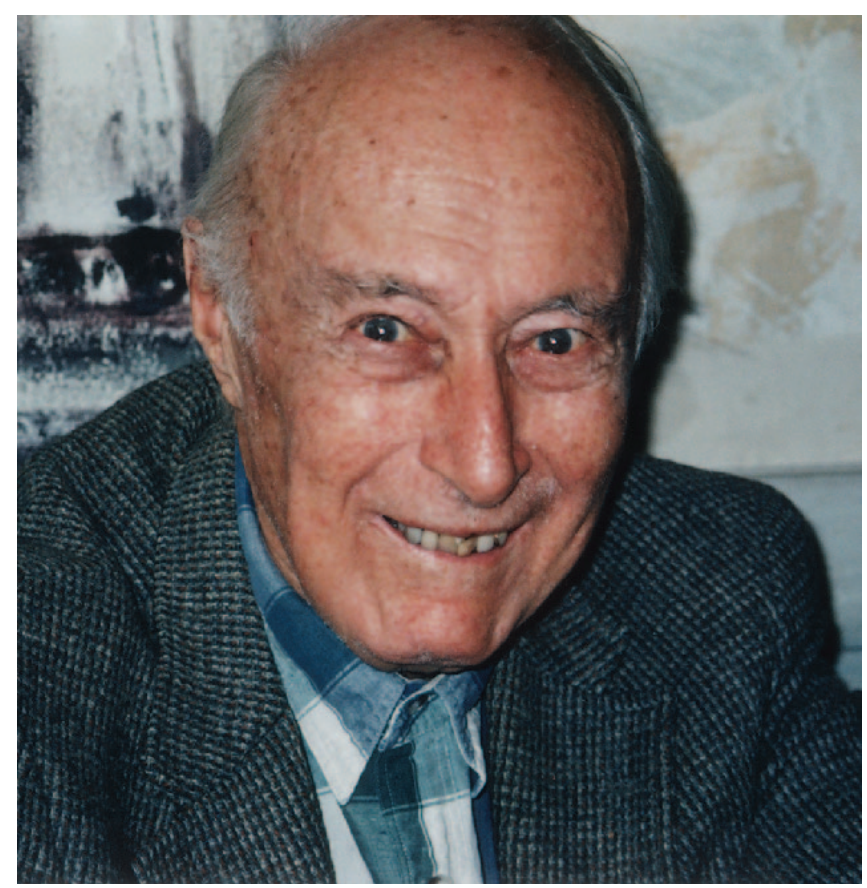

"You know, ...there is no absolute truth in science; truth is a state of mind."19 


\section{Sig: The Person}

Doctor Ramfjord was always courteous. The door to his office on emeritus row at the School of Dentistry was always open to all who came to see him for a visit or for advice. His smile reflected his gracious side, a reflection of his friendly attitude to visitors.

There were times when Sig was pensive, especially when asked a question about the future of periodontics and dental education. When asked about the number of new concepts of periodontal treatment, he responded: New paradigms of periodontal disease will continue to be advanced as long as questions are still being asked about its prevention, diagnosis and treatment. Surely Sig must have been thinking of one of his favorite books, Sofies verden, a novel about the history of philosophy from Socrates to Sartre and beyond. ${ }^{56}$

\section{ACKNOWLEDGMENTS}

I would like to extend a special thanks to Dr. Martha Somerman, University of Michigan School of Dentistry, Ann Arbor, Michigan for her assistance in bringing this paper to publication.

\section{REFERENCES}

1. Pihlstrom BL, Sigurd Ramfjord, Major Ash, Jr. J Dent Res 1997;76:1716-1719.

2. Gottlieb B. Die diffuse Atrophie des Alveolarknochens. $Z$ f Stomat 1923;21:195-147.

3. Orban B. Traumatic occlusion and gum inflammation. J Periodontol 1939;10:262.

4. Gottlieb B, Orban B. Zahnfleischentzündung und Zahnlockerung. Berlin: Berlinische Verlagsanstalt; 1936.

5. Glickman I. Clinical Periodontology. Philadelphia: WB Saunders; 1953.

6. Orban B. Periodontics: A Concept-Theory and Practice. St. Louis: CV Mosby; 1958.

7. Ramfjord SP. Effects of acute febrile diseases on the periodontium of Rhesus monkeys with reference to poliomyelitis. J Dent Res 1951;30:615-626.

8. Ramfjord SP. Tuberculosis and periodontal disease with special reference to collagen fibers. J Dent Res 1952; 31:5-10.

9. Ramfjord SP. Reattachment in periodontal therapy. $J$ Am Dent Assoc 1952;45:513-523.

10. Ramfjord SP. Experimental reattachment in Rhesus monkeys. J Periodontol 1951;22:67-77.

11. Bunting RW. The control and treatment of pyorrhea by subgingival surgery. J Am Dent Assoc 1928;15:119126.

12. Russell AL. A system of classification and scoring for prevalence surveys of periodontal disease. J Dent Res 1956;35:350-359.

13. Ramfjord SP. Indices for the prevalence and incidence of periodontal disease. J Periodontol 1959;30:51-59.

14. Waerhaug J. The gingival pocket. Anatomy, pathology, deepening and elimination. Odontologisk Tidskrift 1952;60(Suppl. 1):5-186.
15. Waerhaug J. Healing of dento-gingival junction following subgingival plaque control. II: As observed on extracted teeth. J Periodontol 1978;49:119-134.

16. Burgett FG, Knowles J, Nissle R, et al. Short-term results of three modalities of periodontal treatment. $J$ Periodontol 1977;48:131-135.

17. Knowles J, Burgett FG, Nissle RR, et al. Results of periodontal treatment related to pocket depth and attachment level. Eight years. J Periodontol 1979;50:225-233.

18. Ramfjord SP, Nissle RR, Shick RA, Cooper H. Subgingival curettage versus surgical elimination of periodontal pockets. J Periodontol 1968;39:167-175.

19. Ramfjord SP. Changing concepts in periodontics. $J$ Prosthet Dent 1984;52:781-786.

20. Schluger S. Osseous resection-a basic principle in periodontal surgery. Oral Surg Oral Med Oral Pathol 1949;2:316-325.

21. Freidman N. Reattachment and roentgenograms. J Periodontol 1958;29:98-111.

22. Hill RW, Ramfjord SP, Morrison EC, et al. Four types of periodontal treatment compared over two years. $J$ Periodontol 1981;52:655-662.

23. Lindhe J, Westfelt E, Nyman S, Socransky S, Heijl L, Bratthall G. Healing following surgical/non-surgical treatment of periodontal disease. A clinical study. $J$ Clin Periodontol 1982;9:115-128.

24. Ainslie PT, Caffesse RG. A biometric evaluation of gingival curettage (II). Quintessence Int 1981;12:609-614.

25. Echeverria JJ, Caffesse RG. Effect of gingival curettage when performed one month after root instrumentation. J Clin Periodontol 1983;10:277-286.

26. Easlick K. An appraisal of present scientific information concerning periodontal disease. J Am Dent Assoc 1952;44:618-758;45:1-38.

27. Ramfjord SP. The periodontal status of boys 11 to 17 years old in Bombay, India. J Periodontol 1961;32:237248.

28. Greene JC. Periodontal disease in India. Report of an epidemiological study. J Dent Res 1960;39:302-312.

29. Harris JE. The U-M's 1969 Expedition to Egypt. J Mich Dent Assoc 1969;51:256-263.

30. Ramsey N. An evaluation of the arithmetic validity of clinical indices. Thesis. Ann Arbor, University of Michigan; 1969.

31. Coyne D. An analysis of calculus indices. Thesis. Ann Arbor, University of Michigan; 1970.

32. Palacios J. Isomorphism of the PDI and linear transformations. Thesis. Ann Arbor, University of Michigan; 1971.

33. Naylor G. Correlation among Ramfjord plaque index, the Ramfjord gingivitis index, and dry weight plaque. Thesis. Ann Arbor. University of Michigan; 1974.

34. Kjome R. Effects of tooth sample selection on the periodontal disease index. Thesis. Ann Arbor. University of Michigan; 1975.

35. Fleiss JL, Park MH, Chilton NW, et al. Representativeness of the "Ramfjord teeth" for epidemiologic studies of gingivitis and periodontitis. Community Dent Oral Epidemiol 1987;15:221-224.

36. Bentley CD, Disney JA. A comparison of partial and full mouth scoring of plaque and gingivitis in oral hygiene studies. J Clin Periodontol 1995;22:131-135. 
37. Massler M, Schour I. The P-M-A index of gingivitis. $J$ Dent Res 1948;28(Spec. Issue):634 (Abstr.)

38. Massler M, Cohen A, Schour I. Epidemiology of gingivitis in children. J Am Dent Assoc 1952;45:319-324.

39. Mühlemann HR, Mazor ZS. Gingivitis in Zurich school children. Helv Odont Acta 1958;2:3-12.

40. Greene JC, Vermillion SR. The Oral Hygiene Index: a method of classifying oral hygiene status. J Am Dent Assoc 1960;68:7-13.

41. Löe H. The gingival index, the plaque index, and the retention index systems. J Periodontol 1967;38:610616.

42. Ramfjord SP, Kerr DA, Ash MM, eds. World Workshop in Periodontics 1966. University of Michigan; Ann Arbor; 1966.

43. Pihlstrom BL, McHugh RB, Oliphant TH, Ortiz-Campos C. Comparison of surgical and non-surgical treatment of periodontal disease. J Clin Periodontol 1983; 10:524-541.

44. Knowles J, Burgett FG, Nissle RR, et al. Results of periodontal treatment related to pocket depth and attachment level. Eight years. J Periodontol 1979;50:225233.

45. Magnusson J, Runstad L, Nyman S, Lindhe H: A long junctional epithelium-A locus minoris resistentiae in plaque infections. J Clin Periodontol 1983;10:333-340.

46. Levine G, Stahl S. Repair following periodontal flap surgery with retention of gingival fibers. J Periodontol 1972;43:99-103.

47. Syed SA, Morrison EC, Lang NP. Effectiveness of repeated scaling and root planing and/or controlled oral hygiene on the periodontal attachment level and pocket depths in beagle dogs. II. Bacteriological findings. J Perodont Res 1982;17:219-225.

48. Ramfjord SP, Nissle RR, Shick RA, Cooper H. Subgingival curettage versus surgical elimination of periodontal pockets. J Periodontol 1968;39:167-175.

49. Nyman S, Lindhe J, Rosling B. Periodontal surgery in plaque-infected dentitions. J Clin Periodontol 1977;4: 240-249.

50. Ramfjord et al. Oral hygiene and maintenance of periodontal support. J Periodontol 1978;53:26-30.

51. Proceedings of the World Workshop in Clinical Periodontics. Chicago: The American Academy of Periodontology; 1989.

52. Goodson JM. Clinical measurements of periodontitis. J Clin Periodontol 1986;13:446-460.
53. Ramfjord SP, Ash MM. Significance of occlusion in the etiology and treatment of early, moderate, and advanced periodontitis. J Periodontol 1981;52:511517.

54. Burgett FG, Nissle RR, Ramfjord SP, et al. A randomized trial of occlusal adjustment in the treatment of periodontitis. J Clin Periodontol 1992;19:381-387.

55. Caton J. Periodontal diagnosis and diagnostic aids. In: Proceedings of the World Workshop in Clinical Periodontics. Chicago: The American Academy of Periodontology; 1989;I-6.

56. Gaarder J. (translated by Paulette Møller). Sophie's World. New York: Berkley Books; 1997 (Originally published in Norwegian under the title Sofies verden 1991 by H. Aschehoug \& Co. Oslo, Norway).

Send reprint requests to: Dr. Major M. Ash, University of Michigan, 1206 Snyder Ave., Ann Arbor, MI 48103. 